\title{
Network destabilization and transition in depression: New methods for studying the dynamics of therapeutic change
}

\author{
Adele M. Hayes, \\ University of Delaware \\ Carly Yasinski, \\ University of Delaware \\ J. Ben Barnes, and \\ University of Delaware \\ Claudi L. H. Bockting \\ Universiteit Utrecht
}

\begin{abstract}
The science of dynamic systems is the study of pattern formation and system change. Dynamic systems theory can provide a useful framework for understanding the chronicity of depression and its treatment. We propose a working model of therapeutic change with potential to organize findings from psychopathology and treatment research, suggest new ways to study change, facilitate comparisons across studies, and stimulate treatment innovation. We describe a treatment for depression that we developed to apply principles from dynamic systems theory and then present a program of research to examine the utility of this application. Recent methodological and technological developments are also discussed to further advance the search for mechanisms of therapeutic change.
\end{abstract}

Pharmacological treatments and cognitive, behavioral, and interpersonal therapies for major depressive disorder (MDD) have efficacy rates of approximately 60\%, and emotion-focused and short-term psychodynamic therapies also show promise (Hollon \& Ponniah, 2010).

Rates of relapse and recurrence are significantly lower with psychotherapy but are still high. Risk increases dramatically with each subsequent episode, and as many as $60 \%$ of individuals who have recovered from a depressive episode will have a recurrence within five years (Solomon et al., 2000). Once the course of depression becomes recurrent or chronic, treatment becomes even more difficult, with remission rates from acute treatment falling below 50\% in intent-to treat samples (Cuijpers et al., 2010; Spijker, van Straten, Bockting, Meeuwissen, \& van Balkom, 2013). We must improve treatments to better address the chronicity of this debilitating disorder.

Correspondence to: Adele M. Hayes, Department of Psychological and Brain Sciences, University of Delaware, Newark, DE 19716 USA. ahayes@udel.edu.

Publisher's Disclaimer: This is a PDF file of an unedited manuscript that has been accepted for publication. As a service to our customers we are providing this early version of the manuscript. The manuscript will undergo copyediting, typesetting, and review of the resulting proof before it is published in its final citable form. Please note that during the production process errors may be discovered which could affect the content, and all legal disclaimers that apply to the journal pertain. 
Recent approaches to understanding psychopathology involve multiple, interacting risk and protective factors (e.g. Hankin, 2015; Hölzel, Härter, Reese, \& Kriston, 2011) and multicomponent networks of symptoms (Borsboom \& Cramer, 2013), yet most psychosocial treatments for depression target an area of functioning thought to be primary in a given theoretical model (e.g., cognitions, behaviors, emotions, interpersonal functioning, or physiology). Treatments that target part of the depressive system, or one or a few of the processes that maintain it, are compared in time-intensive and expensive randomized controlled trials (RCT). These trials have yielded important information about treatment efficacy and a pool of empirically-supported treatments for depression, but little is known about how the different treatments have their effects or how to improve long-term outcomes. This approach to treatment innovation has been slow and incremental.

A number of researchers propose that one of the most efficient routes to optimize and improve treatment efficacy is to take advantage of this rich store of clinical trial data and identify mechanisms of action in these treatments, as well as variables that facilitate or inhibit these change processes (e.g., Barlow, Bullis, Comer, \& Ametaj, 2013; Hayes, Laurenceau, \& Cardaciotto, 2007a; Holmes, Craske, \& Graybiel, 2014; Kazdin, 2011; Lorenzo-Luaces, German, \& DeRubeis, this issue). In addition, the National Institute of Mental Health (NIMH) in the United States now mandates that the next generation of clinical trials assess proposed mechanism(s) of action and examine them as predictors of functional and clinical outcomes (Insel \& Gogtag, 2014). There is in tandem an emphasis on moving beyond a focus on single theoretical orientations to identifying transtheoretical and transdiagnostic processes related to psychopathology and therapeutic change (Barlow et al., 2013; Harvey, Watkins, Mansell, Shafran, 2004; Hersenberg \& Goldfried, 2015). The NIMH Research Domain Criteria (RDoC) were developed to facilitate the discovery of such fundamental processes (Cuthbert \& Insel, 2013; Cuthbert \& Kozak, 2013). It is an exciting time in the process of science, when a substantial body of research accumulates to warrant the search for cross-cutting principles and processes.

One way to stimulate treatment innovation is to build on a broader science of change. Dynamic systems science is revealing common principles of system transformation in physics, biology, chemistry, ecology, political science, and other disciplines. This approach involves the study of relatively stable multi-component patterns (called attractors) rather than single components, as well as feedback processes, pattern destabilization, and the development of new attractors (Thelen \& Smith, 1994; Lewis, 2005). Systems are observed over time, perturbed, and studied intensively at points of transition.

\section{General Framework: Basic Principles of Dynamic Systems Theory Relevant to Psychotherapy}

We describe how the principles and general approach of dynamic systems theory can inform research on how effective psychological treatments move individuals from rigid, disabling patterns to more flexible and adaptive ones. This theoretical framework is based on a distillation of basic concepts at a principle-based level with some adaptation (for more comprehensive presentations, see Granic \& Hollenstein, 2006; Lewis, 2005; Salvatore \& Tschacher, 2012; Schiepek, Eckert, Aas, Wallot., \& Wallot, 2015). Some might argue that 
one aspect or another of the framework is too crude, does not meet the exact specifications of dynamic systems modeling, or does not include important details. Our intent here is to suggest an organizing framework to integrate disparate findings, facilitate comparisons of processes and mechanisms across studies, and suggest methodological innovations. Such a framework can provide new ways of thinking about treatment research and development, although at this point applications of dynamic systems theory to psychotherapy research might represent successive approximations. To realize the full potential of dynamic systems modeling, clinical research will likely involve new types of data collection, new analytic tools, and interdisciplinary collaborations with scientists in other fields such as physics, computational modeling, mathematics, and computer science. New research and methods for studying networks of psychopathology (Borsboom \& Cramer, 2013), emotional inertia (Koval, Pe, Meers, \& Kuppens, 2013), and critical transitions (Sheipek \& Strunk, 2010; Demic \& Cheng, 2014; van de Leemput, et al. 2014) are already moving in this direction. We illustrate how a common organizing framework can integrate these findings into a working model from which to generate new hypotheses and stimulate treatment development.

As we have summarized elsewhere (Hayes \& Yasinski, 2015), a dynamic system consists of multiple components that constantly interact with each other and with internal and external processes to form patterns that change and evolve over time. An adaptive system maintains a dynamic tension between stability and variability (for a review, see Hollenstein, LichtwarckAschoff, \& Potworowski, 2013). When a dynamic system self-organizes, the components settle into preferred and relatively stable patterns, called attractor states. System behavior tends to return to these patterns when perturbed. Attractors that are activated repeatedly over time and contexts are particularly stable. Inhibitory processes maintain system coherence and integrity by absorbing or assimilating perturbations, thus keeping the system organized around the same attractor state(s). Attractors that are entrenched require a significant amount of perturbation to move from these preferred states, whereas those that are less developed or that have been destabilized are changed more easily and allow for adaptation to challenges and changing contexts.

Change involves movement through a series of states of stability, variability, and shifts in attractor states (Thelen \& Smith, 1994). Change can be gradual and linear, but when challenges to the current steady state are too great to assimilate, transitions are often characterized by increased variability in system behavior and discontinuous change, called phase or order transitions (Kelso, Ding, \& Schoner, 1993; Salvatore \& Tschacher, 2012; Scheipek et al., 2015; van Geert \& van Dijk, 2002). During periods of fluctuation, the system is destabilized and therefore more open to new information and potentially more adaptive configurations.

A period of "flickering" (Dakos, van Nes, \& Scheffer, 2013) or oscillating between alternative attractors (e.g. old and new patterns) can precede or accompany transition, until the system settles into a new dynamically stable state. A new attractor can be strengthened and generalized by repeated activation across multiple contexts. This new attractor can then inhibit or compete with the old attractor state(s) to prevent a return to less adaptive 
functioning, or over time it can become the preferred or default attractor state (Kelso et al., 1993; Scheffer et al., 2012; Thelen \& Smith, 1994).

To study change, researchers often conduct perturbation experiments. In this research, the baseline stability of a system is measured, the system is disturbed and observed in transition, and the variables of interest are assessed frequently across trials of the experiment.

Perturbation studies in dynamic systems research using both simulated and real-time data document two early warning signs of system transition: 1) a period of increased variability in system behavior called critical instability (Kelso et al., 1993, Schiepek \& Strunk, 2010; Vallacher, Read, \& Nowak, 2002) and 2) a period of critical slowing, which is an increase in the time or rate of return to the initial equilibrium state following perturbation (Scheffer et al., 2012; van de Leemput, et al. 2014). These indicators of impending transition are reliably quantified by increases in the variance in system behavior and in temporal (lag-1) autocorrelation (extent to which the system becomes increasingly similar between consecutive observations; Dakos et al., 2012a; Dakos, Van Nes, D'Odorico, \& Scheffer, 2012b). Resilience from this perspective is the magnitude of disturbance a system can tolerate before it shifts into a different state.

The study of system behavior in the vicinity of these early indicators of transition has the potential to reveal key mechanisms of change, as well as points of prevention and intervention. For instance, a recent special issue on system shifts and "tipping points" in ecology (Dakos \& Hastings, 2013) provides multiple examples of how the identification of impending critical transitions can prevent the destruction of systems such as coral reefs, waterways, species, rainforest ecosystems, and other such phenomena. The ability to identify such warning signals can also have important implications for the prevention and treatment of depression. For example, Sheipek et al. (2011) illustrate how dynamic systems methods can be used to identify early warning signs of transition and highlight points of intervention for those at high risk for suicide. Similarly, the essence of psychotherapy is to induce and capitalize on openings and transition points to alter the course of maladaptive trajectories of psychopathology.

\section{A Dynamic Systems Framework for Understanding Depression and Its Treatment}

As we have described elsewhere (Hayes \& Strauss, 1998; Hayes, Laurenceau, Feldman, Strauss, \& Cardaciotto, 2007b; Laurenceau, Hayes, \& Feldman, 2007), a dynamic systems perspective can help to integrate aspects of psychopathology research and components of empirically-supported treatments for depression. This framework seems particularly relevant to understand the recurrent and chronic nature of depression.

\section{Network destabilization and transition (NDT) model of therapeutic change}

We propose a model of therapeutic change that integrates research on the psychopathology and treatment of depression and suggests key targets of intervention framed in the context of dynamical systems theory (summarized in Figure 1). This model shares some similarity with Sheipek et al.'s (2015) generic principles of change in therapy, but our model is more 
closely linked with research on mood and anxiety disorders and is the theoretical foundation of exposure-based cognitive therapy (EBCT; Hayes, Ready, \& Yasinski, 2014; Hayes, 2015), a treatment for depression that we developed to apply and test these change principles. We present initial research to examine the process of change in this treatment and end with suggestions for future research, using exciting new methods and technological advances. Such developments might move closer to true dynamical systems modeling and stimulate further treatment innovation.

\section{Multi-modal patterns}

A dynamic systems approach suggests multi-component patterns that a system settles into and returns to, unless perturbations overwhelm the regulatory systems that maintain that organization. Although not framed in the language of dynamic systems theory, a number of theories of therapeutic change in mood and anxiety disorders also propose pathological patterns or associative networks as key targets of intervention, rather than single components of functioning. For instance, fear structures are targeted in anxiety disorders (Lang, 1977; Foa \& Kozak, 1986). Depressive networks, interlocks, and schemata (Beck \& Dozois, 2011; Borsboom \& Cramer, 2013; Teasdale, 1999; van de Leemput, et al. 2014), emotional schemes (Greenberg, 2002), and early maladaptive schemata and modes (Beck, Freeman, \& Davis, 2004; Malogianis, et al., 2014; Young, Klosko, \& Weishaar, 2003) are central targets in treatments for depression and personality disorders. Clinical neuroscience is also shifting from studying discrete brain regions to mapping the connectivity of neural circuits that might be implicated across psychological disorders, using a functional network perspective (Weingarten \& Strauman, 2015).

These various hypothetical patterns (which are most often called networks in psychotherapy research) are thought to consist of interrelated cognitive, affective, behavioral, and physiological components that rigidly maintain pathology, which we and others (e.g., Bystritsky, Nierenberg, Feusner, Rabinovich, 2012; Hayes \& Yasinski, 2015; Sheipek et al, 2015; van de Leemputt et al., 2014) argue function like attractors. In chronic depression, these attractors have a long history and can be particularly difficult to dislodge, as perturbations are likely to be assimilated or deflected by a number of powerful maintaining and inhibitory processes. Psychological treatments can be viewed as a way to destabilize these well-entrenched patterns and also facilitate new learning and the development of more adaptive patterns. Change in these patterns could decrease psychopathology and increase resilience.

\section{Depression as a stuck state}

Holtzheimer and Mayberg (2011) contend that it is time to rethink depression and move from a focus on symptoms to understanding depression as being "stuck in a rut" from which it is difficult to exit. Indeed, depression is increasingly viewed as a problem of capture by negative stimuli and mood states and difficulty disengaging from these states (Disner, Beevers, Haigh, \& Beck, 2011; Farb, Irving, Anderson, \& Segal; 2015; Joorman \& Tanovic, in press; Koster, De Lissnyder, Derakshan \& De Raedt, 2011). In addition, those who are depressed show rigid and stereotyped emotion responses that are insensitive to changes in context and environmental demand (Bylsma, Morris, \& Rottenberg, 2008). Research on 
emotion dynamics demonstrates another type of rigidity in depression, called "emotional inertia," the extent to which negative emotions feed forward to predict and maintain later negative mood (Houben, Van De Noortgate, \& Kuppens, 2013; Koval, Kuppens, Allen, \& Sheeber, 2012; for an exception, see Thompson et al., 2012). Summarizing this line of research, Kuppens and colleagues (2010) conclude that depression represents a negativelyvalenced, low-arousal affective home base, or attractor state, around which emotions fluctuate. Genetic, biological, and environmental factors contribute to individual differences in this home base (Wichers, 2014). Deviations from this baseline that are too great trigger a "pull back" reaction to maintain the default organization. Consistent with this idea, negative emotion inertia predicts less negative emotion recovery after exposure to negative stimuli, which the authors hypothesize to be an impairment in mood repair (Koval et al., in press).

Research on the interconnectivity of networks of emotions or cognitions also indicates a rigidity that must be considered when treating depression. For example, Pe and colleagues (2015) found that those who are depressed (relative to healthy controls) have more densely interconnected networks of negative emotions, as measured by stronger temporal connections between different emotions activated in daily life. The groups did not differ in the density of the positive emotion network, but this measure of density considers only the strength and not the number of connections. The authors also note that the measure of positive emotions did not include the same range of emotions as the measure of negative emotions.

Using a cognitive measure of the associations between ratings of different negative- and positively-valenced adjectives, Dozois and colleagues reported that the negative selfdescriptors of those who are depressed are more strongly interconnected than in normal controls, and the positive descriptors are less strongly interconnected (Dozois \& Dobson, 2001; Dozois \& Frewen, 2006). In addition, more severe symptoms and number of episodes are associated with more interconnectivity of negative self-referent cognitions and less interconnectivity of positive cognitions (Dozois, 2002; Dozois \& Dobson, 2003).

These studies focus on sets of emotions or cognitions, but psychopathology research and a dynamic systems approach suggest that treatments should target and disrupt multi-modal patterns (cognitive, affective, behavioral, somatic) that contribute to depression. In addition, it is critical to address the processes associated with entering and staying in a depressive state.

\section{Self-perpetuating processes}

Three interconnected processes operate in depression to prolong negative mood, increase sensitivity and reactivity to stressful life events, and interfere with adaptive coping and processing of emotional material. Each of these processes inhibits movement from the depression state and must be addressed in order for constructive emotional processing and new learning to occur (Hayes, in press).

Unproductive processing loop-Depression and risk for depression are associated with an unproductive processing loop that is easily activated, captures attention, and is very difficult to disengage. Recent comprehensive reviews on information processing in 
depression (Disner et al., 2011; Farb et al., 2015) highlight two factors that De Raedt and Koster (2010) proposed as key contributors to this vicious cycle: negative attention bias and depressive elaboration. Negative events and stimuli capture and fixate attention, which prolongs negative mood states and activates a depressive elaboration process. Elaboration involves negative self-schemas, rumination, and overgeneralization to events and memories associated with the depressive schemas. This elaboration process can be conditioned over time and become an entrenched habit (Teasdale et al. 2000; Watkins \& Nolen-Hoeksema, 2014), as well as contribute to a narrowing of attentional focus on self-related information (Grol, Hertel, Koster, \& De Raedt, 2015; Whitmer \& Gotlib, 2013). This unproductive processing loop is powerful, overwhelming, and at times associated with suicidality. It is therefore not surprising that one can come to fear the depressive view of the self and experiences that contributed to it, as they can activate the maladaptive loop (Hayes, 2015).

Maladaptive inhibitory control processes-Depression is associated with a combination of hyperactivity of the amygdala and impaired cognitive control in the dorsolateral prefrontal cortex (DLPFC) in response to negative mood stimuli (Disner et al., 2011; De Raedt \& Koster, 2010; De Raedt, Vanderhasselt, \& Baeken, this issue). This pernicious combination perpetuates the unproductive processing loop, as negative emotion, schema activation and spreading, and rumination are easily activated and poorly regulated. With each episode of depression, neural networks for attention, executive control, and cognitive elaboration are hypothesized to become more tightly coupled, thereby lowering the threshold for activation (De Raedt \& Koster, 2010; Farb et al., 2015).

Episodes of unproductive processing often end in exhaustion, avoidance, numbing, and hopelessness, which can function to inhibit the relentless cycle. However, these attempts at regulation are not effective. Chronically avoided depressive material tends to flood forward and intrude (for reviews, see Brewin, Gregory, Lipton, \& Burgess, 2010; Trew, 2011), reactivating the unproductive processing loop, much as is the case with post-traumatic stress disorder (PTSD). Those who are depressed have been found to report intrusions that are of similar frequency and intensity as those with PTSD (Brewin et al., 2010). An avoidant style of coping can have long-term consequences, as avoidance predicted recurrence in a 5.5 year follow-up study of remitted patients with a history of recurrent depression (Bockting et al., 2009).

Dysfunctional positive emotion system-Another process that perpetuates depression and inhibits change is what Disner et al. (2011) aptly call a "positive blockade." These authors review neuroimaging studies that demonstrate not only an attentional bias toward negative stimuli, but also a bias away from positive stimuli. In addition, depression is associated with decreased reward sensitivity and learning and with decreased capacity to recognize, process, and sustain positive emotion, with underpinnings in brain reward pathways (Pizzagali, 2014; Joormann \& Gotlib, 2010). In addition, those who are depressed tend to actively avoid positive emotions and dampen those that are activated (Carl, Soskin, Kerns, \& Barlow, 2013; Dunn, 2012; Joormann \& Gotlib, 2010). The inability to capitalize on the benefits of positive emotion is particularly problematic in recurrent and chronic 
depression and is a significant predictor of relapse (Beshai, Dobson, Bockting, \& Quigley, 2011).

\section{Inhibited emotional processing and learning}

Chronic vacillation between avoidance and ruminative recycling and depressive elaboration can inhibit constructive processing of disturbing emotional experiences (Brewin et al., 2010; Greenberg, 2002; Teasdale, 1999; Watkins, 2008). Problems with the positive emotion system can also interfere with the processing of new and potentially corrective information, as information that is positive in nature is not likely to penetrate the positive blockade. Corrective information and experiences that could destabilize the pathological patterns of depression are likely to be deflected or assimilated into existing schemas rather than induce the dissonance necessary for accommodation and schema change (Carey, 2010; Higginson, Mansell, \& Wood, 2011). Problems updating information, shifting sets, and inhibiting negative emotion material further inhibit new learning (Joorman \& Tanovic, in press; Pe, Raes, \& Kuppens, 2013). Moreover, the positive emotion system cannot be harnessed for its substantial benefits, such as mood repair, buffering or competing with the strong pull into the rut of depression, and "upward spirals" of positive emotion and cognitions that contribute to wellness and resilience (Garland et al., 2010; Garland, Geschwind, Peeters, \& Wichers, 2015; Waugh \& Koster, this issue).

\section{Change processes and new learning}

The maladaptive patterns that maintain depression are easily and often activated and strengthened, and they are further solidified with each episode of depression. Depression is associated with a recurrent unproductive processing loop, failed attempts to inhibit this cycle, and problems activating and processing positive emotions and information. These three processes contribute to an entrenched and self-perpetuating system. Destabilizing patterns with this history is challenging, as perturbations are more easily assimilated than they are to destabilize old patterns.

Instead of targeting a single component of functioning (e.g. cognitions, emotions, behaviors, physiology) or a single perpetuating process in treatment, we propose that it might be more potent to target multi-modal patterns that include the three processes known to maintain depression. Targeted changes to the combination of attentional and processing dysfunctions could increase flexibility and openness to new information and experiences, allow for destabilization of old patterns, and facilitate healthy processing of emotional experiences. It is also important to develop new, more adaptive patterns that can inhibit the powerful pull of the old attractor and with time and repetition, stabilize into a new steady state with potential prophylactic effects.

Exposure and constructive emotional processing-Exposure-based treatments for anxiety and trauma-related disorders provide strategies to target some of the fundamental processes that go awry in depression and enhance emotional processing and new learning. These approaches induce a process of change that is strikingly similar to dynamic systems conceptualizations. Cognitive-behavioral therapies (CBT) for PTSD have particular relevance, given the common therapeutic targets of unproductive processing, intrusion of 
disturbing thoughts, images, and memories, and maladaptive attempts at inhibition (Angelakis \& Nixon, 2015; Brewin et al., 2010). Exposure-based therapies are among the most effective treatments for anxiety and trauma-related disorders (Powers et al., 2010).

A dynamic systems perspective focuses on multi-component patterns and self-perpetuating processes. Exposure therapy involves decreasing pathological avoidance and activating the relevant fear network. This associative network includes cognitions, behaviors, affect, and physiological components (Foa \& Kozak, 1986; Lang 1977), which becomes pathological when it generalizes and is activated in situations that are not inherently threatening. Treatment involves activating the different nodes of the network and exposing patients to novel information that violates expectations, challenges beliefs, and destabilizes the pathological network. This type of treatment induces distress to increase tolerance and then relieve distress. The discrepancy between the old learning and new information creates the opportunity for emotional processing, as indexed by shifts in perspective and meaning, together with new emotional responses (Foa \& Kozak, 1986; Foa, Huppert, \& Cahill, 2006).

In exposure-based treatments for PTSD, the movement from an unproductive processing loop to productive emotional processing involves more than fear reduction. Emotional processing also involves increasing the context specificity of overgeneralized trauma memories, improving discrimination, increasing attention toward information inconsistent with maladaptive beliefs, and making meaning of experiences in the broader context of the person's life (Brewin, 2014; Ehlers \& Clark, 2000; Foa et al., 2006; Resick, Monson, \& Chard, 2014). In addition, exposure therapy has been conceptualized as a way to teach patients to distance (or decenter) from habitual, conditioned fear responses and to increase tolerance for, rather than reduce, distress (Arch, Wolitzky-Taylor, Eifert, \& Craske, 2012). Another facet of exposure-based treatments is affect labeling, or putting words (written or verbal) to emotions, which has been demonstrated to facilitate the effects of exposure and extinction learning (Lieberman et al. 2007; Tabibnia, Lieberman, \& Craske, 2008).

Constructive emotional processing is thought to involve similar components in the treatment of depression (Pascual-Leone, \& Greenberg, 2007; Teasdale, 1999; Watkins, 2008; Wheatley et al., 2007). More emphasis is placed on learning skills to reduce and unhook from powerful pull of rumination, overgeneralization, and hopelessness in depression than in the anxiety disorders (Kuyken et al., 2010; Teasdale et al., 2000).

Another principle of dynamic systems theory is that new attractors can inhibit entry back to old attractors and over time can become the default attractor. Recent developments in human and animal learning research are quite consistent with this. Research on the neuroscience of memory suggests that reactivating old learning can make it more labile and plastic. With reactivation, old learning either can be reconsolidated and strengthened, or if novel and unexpected information is presented at this time, the old memory can be updated (Nadel, Hupbach, Gomez, \& Newman-Smith, 2012). In addition to weakening pathological learning, more emphasis is being placed on strengthening new learning over time and contexts and increasing accessibility so that it can inhibit or compete with the pathological learning (Bouton, 2002; Craske, Liao, Brown, \& Vervliet, 2012; Foa et al., 2006). Depression researchers similarly have begun to emphasize not only destabilizing depressive networks, but also generating and consolidating new, more positive and adaptive learning (Carl et al., 
2013; Dozois et al., 2014; Dunn, 2012, Waugh \& Koster, this issue). Consistent with this idea of inhibitory learning, our research group (Ready et al., in press) found that more overgeneralization during the narrative phase of trauma-focused CBT for youth predicted worse outcomes over the 12-month follow-up, but that new learning related to traumarelated beliefs reduced those negative effects. Although preliminary, these findings highlight the potential importance of compensatory or inhibitory learning and of elaborating and solidifying this new learning for relapse prevention.

Therapeutic gains can also facilitate "upward spirals" health and resilience (Garland et al., 2010; Garland et al., 2015; Waugh \& Koster, this issue). An adaptive system maintains coherence but also flexibility and openness to new information and changing circumstances, which allows for growth. Flexibility is considered a fundamental aspect of system resilience and adaptation (Hollenstein et al, 2013), as well as mental health (Kashdan \& Rottenberg, 2010). Waugh and Koster (this issue) describe strategies that can facilitate resilience and help prevent recurrence in depression, such as improving the ability to recover from daily and major stressors, increasing positivity, and training flexibility in responding to changing environmental demands.

\section{Summary}

The NDT model (Figure 1) proposes that therapeutic change in depression involves first reducing the self-perpetuating factors, which include an unproductive processing loop, maladaptive inhibitory control systems, and a positive blockade (panel A). A decrease in these inhibitory factors can allow new information and experiences to penetrate the depressive network. Second (panel B), the multiple nodes of the depressive network are activated, and new information and experiences inconsistent with old learning can destabilize the depressive network. Therapists can then facilitate constructive processing of memories associated with the depressive elaboration process. This phase should be associated with a transient increase in depressive symptoms, an increase in the variability of the depressive network, and more emotional processing. Third (panel C), the positive pattern is activated, exercised, and elaborated. This phase should be associated with more positive pattern activation, which should predict better functioning after treatment. In short, therapeutic change is likely to involve disrupting old, well-worn patterns and developing new, more adaptive configurations of cognition, emotions, behaviors, and somatic functioning that, with repetition across contexts, can evolve into new attractors.

\section{Application: Exposure-Based Cognitive Therapy for Depression}

A number of treatments for depression acknowledge to some extent the importance of exposure and emotional processing principles in the treatment of depression, but the therapies often focus on one or a few parts of the larger picture of system change (e.g. working through disturbing emotions, decreasing avoidance and rumination, increasing decentering). We developed an integrative treatment, exposure-based cognitive therapy (EBCT; for clinical details see Hayes, 2015; Hayes et al., 2014) that is built on a cognitive therapy foundation and applies principles from dynamic systems theory and strategies from exposure-based treatments for anxiety and trauma-related disorders. EBCT targets each of the components of the NDT model rather than one or a few of the processes. It includes 21 
sessions delivered in three phases: stress management, exposure and emotional processing, and positive growth. Written narratives are included throughout the course of treatment as one form of exposure to increase engagement with disturbing material and facilitate processing between sessions.

We present a brief overview of EBCT, but the focus of this paper is on the treatment as a medium for examining a dynamic systems model of therapeutic change. EBCT is delivered in three phases that follow a dynamic systems approach to inducing change. A phase design provides a useful way to examine the process of change because the temporal sequencing of the interventions is clear. The first phase of EBCT involves: a) identifying the components of the individual's depressive network (attractor), b) teaching healthy lifestyle habits and mindfulness meditation to build resources for change, and c) reducing the unproductive processing loop, avoidance, and positive blockade, which are key inhibitors of change (Figure 1, panel A). The second phase involves activating and destabilizing the depressive network and facilitating constructive emotional processing, using a blend of exposure and cognitive therapy techniques (Figure 1, panel B). The final phase of EBCT aims to elaborate and strengthen a new attractor of healthy cognitive, affective, behavioral, and somatic functioning that has the potential to compete with or inhibit the depressive network (Figure 1, panel C). This phase is particularly important for relapse prevention. Thus, exposure principles are applied in four ways across the course of EBCT: a) weekly narratives that patients write about their depression to activate emotions and put them into words; $b$ ) mindfulness meditation exercises to teach patients to decenter from and tolerate difficult emotions; c) the activation and processing of memories related to themes of defectiveness, failure, and worthlessness (Phase 2); and d) developing and exercising the positive emotion system, which activates fear, bracing for loss, and urges to avoid or dampen positive emotions.

EBCT has been associated with significant improvement in depression and large effect sizes in three clinical trials: an open trial conducted by our team (Hayes, Beevers, Feldman, Laurenceau, \& Perlman, 2005; Hayes et al. 2007c), an open trial of a German version of EBCT conducted in Switzerland (Grosse-Holtforth et al., 2012), and a randomized controlled trial (Grosse-Holtforth et al., 2015) of the German version of EBCT compared with a German version of CBT (Hauzinger, 2003). In addition, EBCT is associated with significant decreases in avoidance and rumination and with increases in mindfulness (Kumar, Feldman, \& Hayes, 2008). Thus, the initial findings on the efficacy of EBCT are quite promising.

\section{Application: The Study of Change}

A dynamic systems framework suggests several guidelines for studying the process of change in psychotherapy:

1. Identify and monitor maladaptive interconnected patterns that contribute to psychopathology rather than single variables.

2. Assess how entrenched and rigid maladaptive patterns are to determine the extent of perturbation needed to destabilize them and facilitate change. Patterns that are 
less entrenched might be more easily changed and moved in a more gradual, linear way.

3. Assess processes that perpetuate and maintain maladaptive patterns.

4. Track change during and after the course of treatment, using intensive individual time course data.

5. Assess more than linear, gradual change. Consider also quadratic and cubic patterns.

6. Identify and study transition points (marked by discontinuities in individual time course data and periods of increased variability or critical slowing), which can reveal key mechanisms of change and points of prevention and intervention.

7. Disturbance can appear to be a transient period of worsening, but if negotiated properly, can facilitate change from old patterns and allow for the development of new, more adaptive patterns of functioning.

8. Assess not only maladaptive patterns, but also the breadth and strength of more adaptive patterns that might help to prevent relapse and recurrence.

We describe how we have applied this approach in our initial studies of the change process in EBCT and also describe new methods and statistical advances that might improve this line of mechanism research. Because EBCT is designed to be delivered in three phases that align with a dynamic systems model of change, it provides a method to begin to examine whether the depressive network is destabilized in the exposure phase of treatment (phase 2), or whether it remains intact and a new pattern of more adaptive functioning develops to inhibit its activation or buffer its effects. If destabilization does occur in the second phase of EBCT, it is also possible to investigate whether constructive emotional processing occurs during this turbulence and predicts better outcomes, as is hypothesized in exposure-based treatments for anxiety disorders (Foa et al., 2006). The phase design also allows for analyses of whether processing in the exposure phase predicts the development of new, more positive patterns of functioning in the last phase of treatment.

As in exposure therapy for anxiety and trauma-related disorders, our research suggests that the exposure phase of EBCT is associated with affective arousal, but in the form of transient spikes in depressive symptoms rather than spikes in anxiety. We have found a cubic pattern of symptom change in the three clinical trials of EBCT (Hayes et al., 2007; Grosse Holtforth et al., 2012; Grosse Holtforth et al., 2015). This pattern is characterized by a decrease in depression symptoms in the first phase of treatment, an increase as the depression network is activated, and then a decrease in symptoms. Ratings of patients' weekly narratives, using the CHANGE coding system (Hayes, Feldman, \& Goldfried, 2006), revealed that more emotional processing occurred during this period of worsening, and only emotional processing during this phase (and not earlier) predicted improvement in depression. In addition, higher levels of processing were associated with lower levels of avoidance and with more hope and positive view of self (Hayes et al., 2005). Emotional processing (measured by self-report) in the exposure phase of EBCT again predicted improvement in depression in the two Swiss trials (Grosse Holtforth et al., 2012; Grosse Holtforth et al. 
2015). In the RCT, more emotional processing in the exposure phase of EBCT predicted improvement in depression at the end of treatment, but not in CBT. Affective arousal and emotional processing have also been reported to be significant predictors of outcome in emotion-focused therapy (Pascual-Leone \& Greenberg, 2007; Pos, Greenberg, Goldman \& Korman, 2003). Thus, emotional processing seems to occur during a period of transient symptom exacerbation, which could reflect the destabilization of the depressive network (attractor).

In a recently completed study (Hayes, Yasinski, Ready, \& Laurenceau, 2015), we examined whether constructive emotional processing in EBCT involves destabilization of the depressive network and also the development of a more adaptive associative network, consistent with views of change in dynamic systems theory (Hollenstein et al., 2013) and modern emotional processing theory for anxiety disorders (Craske et al., 2012; Foa et al, 2006). Narratives that patients wrote each week were coded (using the CHANGE coding system) for cognitive, affective, and behavioral components of a depressive network and also for a positive network of functioning that included the same components.

Briefly, a computer program called GridWare (Lamey et al., 2004; Hollenstein, 2007) was used to create individual state space grids for each patient over each of the three phases of EBCT. Gridware is designed to depict visually and quantify dynamic systems variables, such as the extent of stability or spread (dispersion) of system behavior across time. Positive network activation and maladaptive (depressive) network activation variables were created to operationalize the extent to which the cognitive, affective, and behavioral nodes of the depressive or positive network were activated in a given session narrative. Each node (cognitive, affective, behavioral) was considered activated if it was rated as occurring at a moderate (CHANGE rating of 2) to high level (rating of 3 ) in the narratives. To create final depressive and positive network activation scores, the extent of depressive or positive node activation was summed for that narrative. Total scores could range from 0 to 3 nodes activated in the depressive or the positive network for each participant, at each session, and in each of the three phases of treatment. A phase of EBCT included approximately 8 sessions.

From these network activation data, network dispersion and extent of activation in the negative and positive network regions can be quantified. Network destabilization was captured by a dispersion variable, which is the variance or "spread" of the negative and positive activation scores across the grid in a given phase ( 8 sessions) of therapy (see Figure 2). More network stability is characterized by less movement across the cells of the grid in a given amount of time (Figure 2, panel A), and less stability is characterized by a wider range of movement (Figure 2, panel B). These dispersion scores can then be used in analyses.

Areas of state-space grids were used to determine the percentage of sessions in the depressive or positive regions of the grid for each treatment phase. The depressive region included sessions with depressive activation scores of 2 or 3 , and the positive region was defined in the same way, using the positive network activation scores (Figure 3). Extent of network activation in the depressive and positive regions was calculated by dividing the number of sessions a participant spent in the negative or positive regions of the state-space 
grid by the total number of sessions during that phase of treatment. For the patient depicted in Figure 3,75\% of the network activation in that treatment phase was in the depressive region and $50 \%$ in the positive region. These regions of activation indices for each individual can then be used in analyses.

As predicted, more destabilization of the depressive network (higher dispersion scores) during the exposure phase of EBCT was associated with more constructive emotional processing, which then predicted more network activation in the positive region in the last phase of treatment. The end phase positive network activation, in turn, predicted lower depression scores three months after treatment was completed. We assessed depressive and more positive networks with cognitive, affective, and behavioral components, but our findings are consistent with research by Dozois and colleagues (Dozois et al., 2009; Dozois \& Dobson, 2001; Dozois et al., 2014) that focuses on a single cognitive component. They demonstrated that the interconnectedness and strength of both negative and positive selfschemas change with cognitive therapy.

Consistent with the integrative NDT model (Figure 1), this initial line of research suggests that therapeutic change in EBCT involves: 1) reducing rumination and avoidance, 2) activating and destabilizing the depressive network (indexed by the cubic pattern of depressive symptom change and more dispersion), 3) facilitating constructive emotional processing, and 4) developing new, more adaptive configurations of cognition, emotions, and behaviors, which in turn predicted lower depression scores three months after treatment. As in exposure-based treatments for anxiety and trauma-related disorders and emotionfocused therapy for depression, therapeutic change might involve some disturbance to relieve emotional pain (Foa et al., 2006; Pascale-Leone \& Greenberg, 2007), and new learning might help to inhibit the depressive network, although this latter point remains to be tested. These findings, if replicated, could have important clinical implications, as clinicians might be particularly reluctant to induce therapeutic disturbance when treating depression.

Although we examined a dynamic systems model of change in the context of EBCT, we hypothesize that this process of change is likely to apply to other forms of treatment, as it is a broad model of general system change. For example, we found a similar pattern of change in cognitive therapy for Cluster C personality disorders (Beck et al., 2004), most of whom had comorbid depression (Hayes \& Yasinski, 2015). It is important to note, however, that change can also occur in a more gradual and linear way. The more turbulent type of change that we describe is only one form of transition (Hayes et al., 2007a), but it might be particularly relevant for chronic and treatment-resistant depression, which involves maladaptive and deeply entrenched patterns that might function like attractors.

Psychological treatments can also do more to capitalize on the potent effects of positive emotion (Carl et al. 2013; Dunn, 2012; Garland et al., 2010). Although further testing is warranted, adaptive and flexible patterns of thinking, feeling, and behaving can be exercised and might settle into new attractors that could increase resilience and perhaps reduce the substantial risk of relapse and recurrence (Bouton, 2002). 


\section{New Methods and Technological Advancements for the Study of Change}

The approach to studying the process of change that we describe moves from pre-post designs of single variables to analyses of individual time-course data, discontinuities in symptom trajectories, and multimodal networks of psychopathology and networks of more adaptive functioning. Using dynamic systems theory as a conceptual framework, however, is not the same as conducting true dynamic systems analyses and modeling. Nonetheless, the general approach of perturbing an entrenched system and tracking change in perpetuating factors, constructive processing (a potential mechanism of change), and old and new patterns (or attractors) can provide a useful way of understanding therapeutic change. We have generated testable hypotheses that can be investigated further in larger samples with more frequent assessments of process and outcome variables. This would allow for more precise temporal sequencing of the variables and a finer degree of resolution. We describe below some exciting new methods and technologies that could enhance the study of change and bring psychotherapy research closer to dynamic systems modeling.

More sophisticated measures of networks, rigidity, and transition require more frequent assessment of the variables of interest. Time series analyses require frequent, continuous, and equidistant measurements (Sheipek et al., 2015). However, researchers must consider burden to participants and the importance of assessing the full course of treatment rather than one or two-week bursts of time. Another important consideration is that therapy is a perturbation that is meant to induce change. Therefore, methods must be able to model movement across the course of therapy and not require assumptions of stationarity. Many of the approaches we describe below use experience sampling methodology (ESM) to achieve this level of data density, and this method could be incorporated into assessment, both during and after treatment. This approach to intensive data collection also allows for persontailored feedback, which could facilitate the transfer of therapy to everyday life and provide a useful tool to decrease the risk of relapse (e.g., Heron \& Smyth, 2010; Shiepek et al., 2015; Wichers et al., 2011).

\section{Networks and patterns}

A number of methods for quantifying networks could significantly improve the detail and kinds of questions that can be investigated in psychotherapy research. Borsboom and colleagues have developed a sophisticated method to characterize network architecture (for a review, see Borsboom \& Cramer, 2013). This mostly has been applied to networks of symptoms but could also be applied to the study of how multimodal cognitive-emotionalbehavioral-somatic patterns of risk and resilience change over the course of treatment and after treatment is completed. This method can be used to quantify such variables as the density of interconnections, centrality of each of the nodes in a network, and the threshold of activation. This method would have to be able to characterize two attractors and movement over time to capture the dynamics of change in therapy. Bringmann et al. (2013) describe a method for applying network analyses to longitudinal data collected through experience sampling methodology. This approach uses multilevel vector autoregression (VAR), which combines between-subject and within-subject information in a multilevel framework. The information from these analyses can then be analyzed through network analysis techniques 
and visualized through the R-package, qgraph (Epskamp, Cramer, Waldorp, Schmittmann, \& Borsboom, 2012). Wichters (2014) describes a way to model more than symptoms and to combine contextual factors, affect, and behavior in a single network.

\section{Attractor strength}

Although applied to the study of borderline personality disorder, Ebner-Preimer et al. (2015) illustrate in three electronic diary studies how to capture emotion dynamics in response to personally relevant stimuli in patients' lives. Emotion is only one component, but these methods could potentially apply to the study of networks of cognitions, emotion, behaviors and somatic functioning that are targeted in treatment. The authors illustrate how to capture the home base or baseline of a given variable (attractor), the variability (changes around the affective home base in response to internal or external events), and attractor strength, which they define as the pull back to the home base. They illustrate how to compute and analyze these variables using multilevel regression modeling and diffusion modeling to illustrate the strengths and weaknesses of both statistical approaches. These methods could be particularly useful to study change in psychotherapy. Fisher, Newman, and Molenaar (2011) also describe useful techniques for analyzing pattern order and flexibility, using spectral power analyses and dynamic factor models.

\section{Destabilization and transition}

A number of dynamic systems modeling tools are available at the early warning signs of transition toolbox website: www.early-warning-signals.org. These methods can be used to quantify and analyze critical instabilities and critical slowing (Scheffer et al., 2012) in a range of complex systems. With intensive data collection, some of these tools could be useful to study the process of change in therapy.

In psychology, van de Leemput et al (2014) illustrate how to model variability and critical slowing in computer simulations as participants transition in and out of depressed states. Demic and Cheng (2014) describe a computation modeling approach that can capture the dynamics of major depressive disorder episodes, as well as factors that influence these dynamics. Steinacher and Wright (2013) also illustrate simulation models of behavioral activation regulation and transitions in and out of bipolar and non-bipolar states. These methodologies could be particularly relevant to the study of treatments for depression, especially over the period after treatment when the risk of relapse is highest. The state-space grid (SSG) methodology of Gridware that we described in our research can be used to capture a wide range of phenomena relevant to the study of change in psychotherapy, including system rigidity, flexibility, and destabilization (for a review, see Howerter, Hollenstein, Boon, Neimeyer, \& Brule, 2012).

Sheipek and colleagues (2015) have developed the Synergetic Navigation System (SNS), an ambulatory and real-time monitoring system that provides intensive assessment of process and outcome variables and tools for time series analyses. The SNS is a comprehensive tool for studying the process of change that is based on synergetics, an approach that has considerable overlap with dynamic systems theory. A variety of questionnaires and rating systems can be programmed into the system so that different components of a network (e.g. 
cognitive, affective, behavioral, somatic) can be measured. The SNS includes measures of attractor strength and dynamic complexity to identify nonstationarity and critical instabilities. Dynamic complexity identifies jumps, volatility, and pattern complexity of signals. Data are analyzed using a variety of time series procedures, and the output is provided quickly and in a user-friendly and visual way so that it can be used clinically to give patients feedback and guide clinical decision-making. A dashboard system has been developed to give feedback on risk and protective factors as the person goes through the course of treatment.

The SNS can also be used to identify upcoming transitions to indicate when to initiate fMRI assessments (or other physiological measures) to investigate, for example, whether order transitions of brain activity are related to psychological changes during the psychotherapy process (Schiepek et al., 2013). This opens exciting possibilities of mapping therapy processes on to brain activity and perhaps to change in the neural circuits related to rumination, attention and cognitive control, and emotion regulation (De Raedt \& Koster, 2010; Farb et al., 2015; Weingarten \& Strauman, 2015).

\section{Resilience}

In addition to measuring the strength of patterns of more positive functioning, resilience could be assessed during and after treatment using challenge paradigms (Waugh \& Koster, this issue) or ongoing assessment of how individuals process negative and positive events in their lives (e.g. Koval et al., in press; Thompson et al., 2012). Wichers and colleagues (2011) illustrate this method in the context of providing person-tailored feedback in everyday life. Another approach is to examine the carryover or degree of transfer (or persistence) of positive emotions or adaptive responses (Höhn et al., 2013) or upwards spirals of positive emotion and cognitions (Garland et al., 2015), using multilevel and autoregressive latent trajectory modeling analyses. Time-series panel analysis (TSPA; Ramseyer, Kupper, Caspar, Znoj, \& Tschacher, 2014) also can be used to examine sessionto-session change in multiple variables and to analyze patterns of change and temporal feedback loops, which could be particularly useful for modeling positive growth.

\section{Conclusion}

Dynamic systems theory can provide a framework to study and perhaps increase the potency of treatments for depression by conceptualizing the task of therapy as one of changing any entrenched system in nature. The proposed network destabilization and transition (NDT) model of therapeutic change describes key processes that go awry in depression and suggests targets for change. New treatments can be developed to mobilize these change processes in more specific and direct ways, considering depression as a dynamic, ongoing process rather than as a discrete episode. With new tools and technological advances, more questions can be examined to get closer to the core mechanisms of therapeutic change. For instance, future research can examine the extent to which the depressive network can or needs to be changed, the extent to which new learning and adaptive patterns of functioning can inhibit the depressive patterns, and if that alone is sufficient for lasting change without altering the depressive network. The architecture and interconnections of the depressive 
network itself can be investigated as it changes over time. The parameters of therapeutic destabilization could also be delineated to estimate when this is necessary and under what conditions it is most likely to be helpful. Finally, we can enhance the generalizability of our interventions and facilitate growth beyond the acute phase of treatment. Electronic tools, such as web-based programs and smartphone applications, can provide ongoing monitoring and feedback on risk and resilience factors, as patients engage in their everyday lives during and after treatment. Such advances might not only improve the kind of research that can be conducted, but also significantly reduce the chronicity of depression, as therapy is transported into the lives of those we treat.

\section{Acknowledgements}

This describes research based on funding from the National Institute of Mental Health (R01-MH086558 and R21MH062662).

\section{References}

Angelakis S, Nixon RDV. The comorbidity of PTSD and MDD: implications for clinical practice and future research. Behaviour Change. 2015; 32(1):1-25.

Arch JJ, Wolitzky-Taylor KB, Eifert GH, Craske MG. Longitudinal treatment mediation of traditional cognitive behavioral therapy and acceptance and commitment therapy for anxiety disorders. Behaviour Research and Therapy. 2012; 50(7-8):469-478. [PubMed: 22659156]

Barlow DH, Bullis JR, Comer JS, Ametaj AA. Evidence-based psychological treatments: an update and a way forward. Annual Review of Clinical Psychology. 2013; 9:1-27.

Beck AT, Dozois DJA. Cognitive Therapy: Current status and future directions. Annual Review of Medicine. 2011; 62:397-409.

Beck, AT.; Freeman, A.; Davis, DD. Cognitive therapy of personality disorders. 2nd ed.. New York, NY, US: Guilford Press; 2004.

Beshai S, Dobson KS, Bockting CLH, Quigley L. Relapse and recurrence prevention in depression: Current research and future prospects. Clinical Psychology Review. 2011; 31(8):1349-1360. [PubMed: 22020371]

Bockting CLH, Spinhoven P, Wouters LF, Koeter MWJ, Schene AH. the DELTA study group Longterm effect of preventive cognitive therapy in re- current depression: 5.5-year follow-up. Journal of Clinical Psychiatry. 2009; 70(12):1621-1628. [PubMed: 20141705]

Borsboom D, Cramer AO. Network analysis: An integrative approach to the structure of psychopathology. Annual Review of Clinical Psychology. 2013; 9:91-121.

Bouton ME. Context, ambiguity, and unlearning: Sources of relapse after behavioral extinction. Biological Psychiatry. 2002; 52(10):976-986. [PubMed: 12437938]

Brewin CR, Gregory JD, Lipton M, Burgess N. Intrusive images in psychological disorders: Characteristics, neural mechanisms, and treatment implications. Psychological Review. 2010; 117(1):210-232. [PubMed: 20063969]

Bringmann LF, Vissers N, Wichers M, Geschwind N, Kuppens P, Peeters F, Borsboom D, Tuerlinckx F. A network approach to psychopathology: new insights into clinical longitudinal data. PLoS ONE. 2013; 8

Bylsma LM, Taylor-Clift A, Rottenberg J. Emotional reactivity to daily events in major and minor depression. Journal of Abnormal Psychology. 2011; 120(1):155-167. [PubMed: 21319928]

Bystritsky A, Nierenberg AA, Feusner JD, Rabinovich M. Computational nonlinear dynamical psychiatry: A new methodological paradigm for diagnosis and course of illness. Journal of Psychiatric Research. 2012; 46(4):428-435. [PubMed: 22261550]

Carey TA. Exposure and reorganization: The what and how of effective psychotherapy. Clinical Psychology Review. 2010 
Carl JR, Soskin DP, Kerns C, Barlow DH. Positive emotion regulation in emotional disorders: A theoretical review. Clinical Psychology Review. 2013; 33(3):343-360. [PubMed: 23399829]

Craske MG, Liao B, Brown L, Vervliet B. Role of inhibition in exposure therapy. Journal of Experimental Psychopathology. 2012; 3(3):322-345.

Cuijpers P, van Straten A, Schuurmans J, van Oppen P, Hollon SD, Andersson G. Psychotherapy for chronic major depression and dysthymia: A meta-analysis. Clinical Psychology Review. 2010; 30(1):51-62. [PubMed: 19781837]

Cuthbert BN, Insel TR. Toward the future of psychiatric diagnosis: The seven pillars of RDoC. BMC Medicine. 2013; 11:126. [PubMed: 23672542]

Cuthbert BN, Kozak MJ. Constructing constructs for psychopathology: The NIMH research domain criteria. Journal of Abnormal Psychology. 2013; 122(3):928-937. [PubMed: 24016027]

Dakos V, Carpenter SR, Brock WA, Ellison AM, Guttal V, Ives AR, Scheffer M. Methods for detecting early warnings of critical transitions in time series illustrated using simulated ecological data. PLoS One. 2012a; 7

Dakos V, Hastings A. Editorial: special issue on regime shifts and tipping points in ecology. Theoretical Ecology. 2013; 6(3):253-254.

Dakos V, Van Nes EH, D’Odorico P, Scheffer M. Robustness of variance and autocorrelation as indicators of critical slowing down. Ecology. 2012b; 93:264-271. [PubMed: 22624308]

Dakos V, Van Nes EH, Scheffer M. Flickering as an early warning signal. Theoretical Ecology. 2013; 6:309-317.

De Raedt R, Koster EH. Understanding vulnerability for depression from a cognitive neuroscience perspective: A reappraisal of attentional factors and a new conceptual framework. Cognitive, Affective, \& Behavioral Neuroscience. 2010; 10(1):50-70.

De Raedt R, Vanderhasselt MA, Baeken C. Neurostimulation as an intervention for treatment resistant depression: From research on mechanisms towards targeted neurocognitive strategies. Clinical Psychology Review. (this issue).

Disner SG, Beevers CG, Haigh EAP, Beck AT. Neural mechanisms of the cognitive model of depression. Nature Reviews Neuroscience. 2011; 12(8):467-477.

Dozois DJA. Cognitive organization of self-schematic content in nondysphoric, mildly dysphoric, and moderately-severely dysphoric individuals. Cognitive Therapy and Research. 2002; 26:417-429.

Dozois DJA, Bieling PJ, Evraire LE, Patelis-Siotis I, Hoar L, Chudzik S, Westra HA. Changes in core beliefs (early maladaptive schemas) and self-representation in cognitive therapy and pharmacotherapy for depression. International Journal of Cognitive Therapy. 2014; 7(3):217-234.

Dozois DJA, Dobson KS. A longitudinal investigation of information processing and cognitive organization in clinical depression: Stability of schematic interconnectedness. Journal of Consulting and Clinical Psychology. 2001; 69(6):914-925. [PubMed: 11777119]

Dozois DJA, Dobson KS. The structure of the self-schema in clinical depression: Differences related to episode recurrence. Cognition and Emotion. 2003; 17:933-941.

Dozois DJA, Frewen PA. Specificity of cognitive structure in depression and social phobia: A comparison of interpersonal and achievement content. Journal of Affective Disorders. 2006; 90:101-109. [PubMed: 16343641]

Dozois DJA, Bieling PJ, Patelis-Siotis I, Hoar L, Chudzik S, McCabe K, Westra HA. Changes in selfschema structure in cognitive therapy for major depressive disorder: A randomized clinical trial. Journal of Consulting and Clinical Psychology. 2009; 77:1078-1088. [PubMed: 19968384]

Dunn BD. Helping depressed clients reconnect to positive emotion experience: Current insights and future directions. Clinical Psychology and Psychotherapy. 2012; 19:326-40. [PubMed: 22674611]

Ebner-Priemer, Ulrich W.; Houben, Marlies; Santangelo, Philip; Kleindienst, Nikolaus; Tuerlinckx, Francis; Oravecz, Zita; Kuppens, Peter. Unraveling affective dysregulation in borderline personality disorder: A theoretical model and empirical evidence. Journal of Abnormal Psychology. 2015; 124(1):186-198. http://dx.doi.org/10.1037/abn0000021. [PubMed: 25603359]

Ehlers A, Clark DM. A cognitive model of posttraumatic stress disorder. Behaviour Research and Therapy. 2000; 38:319-345. [PubMed: 10761279]

Epskamp S, Cramer AOJ, Waldorp LJ, Schmittmann VD, Borsboom D. Qgraph: Network visualizations of relationships in psychometric data. Journal of Statistical Software. 2012; 48:1-18. 
Farb NAS, Irving JA, Anderson AK, Segal ZV. A two-factor mofel of relapse/recurrence vulnerability in unipolar depression. Journal of Abnormal Psychology. 2015; 124(1):38-53. http://dx.doi.org/ 10.1037/abn0000031. [PubMed: 25688431]

Fisher AJ, Newman MG, Molenaar PCM. A quantitative method for the analysis of nomothetic relationships between idiographic structures: Dynamic patterns create attractor states for sustained posttreatment change. Journal of Consulting and Clinical Psychology. 2011; 79(4):552-563. [PubMed: 21707138]

Foa, EB.; Huppert, JD.; Cahill, SP. Emotional processing theory: An update. In: Rothbaum, BO., editor. Pathological anxiety: Emotional processing in etiology and treatment. New York, NY, US: Guilford Press; 2006. p. 3-24.

Foa EB, Kozak MJ. Emotional processing of fear: Exposure to corrective information. Psychological Bulletin. 1986; 99(1):20-35. [PubMed: 2871574]

Garland EL, Fredrickson B, Kring AM, Johnson DP, Meyer PS, Penn DL. Upward spirals of positive emotions counter downward spirals of negativity: Insights from the broaden-and-build theory and affective neuroscience on the treatment of emotion dysfunctions and deficits in psychopathology. Clinical Psychology Review. 2010; 30(7):849-864. [PubMed: 20363063]

Garland EL, Geschwind N, Peeters F, Wichers M. Mindfulness training promotes upward spirals of positive affect and cognition: multilevel and autoregressive latent trajectory modeling analyses. Frontiers of Psychology. 2015; 6(15):1-13.

Granic, I.; Hollenstein, T. A survey of dynamic systems methods for developmental psychopathology. In: Cicchetti, In D.; Cohen, DJ., editors. Developmental psychopathology, vol 1: Theory and method. 2nd ed.. Hoboken, NJ, US: John Wiley \& Sons Inc; 2006. p. 889-930.

Greenberg LS. Integrating an emotion-focused approach to treatment into psychotherapy integration. Journal of Psychotherapy Integration. 2002; 12(2):154-189.

Grol M, Hertel PT, Koster EHW, De Raedt R. The effects of rumination induction on attentional breadth for self-related information. Clinical Psychological Science. 2015:1-12.

Grosse Holtforth M, Krieger T, Altenstein D, Dörig N, Meisch L, Hayes AM. Exposure-Based Cognitive Therapy as an intervention to foster emotional processing in depression: A randomized comparison with Cognitive-Behavioral Therapy. Manuscript submitted for publication. 2015

Grosse Holtforth AM, Sutter M, Wilm K, Schmied E, Laurenceau JP, Caspar F. Fostering cognitiveemotional processing in the treatment of depression: A preliminary investigation in ExposureBased Cognitive Therapy (EBCT). Psychotherapy and Psychosomatics. 2012; 89:259-260. [PubMed: 22678232]

Hankin BL. Depression from childhood through adolescence: risk mechanisms across multiple systems and levels of analysis. Current Opinion in Psychology. 2015; 4:13-20. http://dx.doi.org/10.1016/ j.copsyc.2015.01.003. [PubMed: 25692174]

Harvey, AG.; Watkins, E.; Mansell, W.; Shafran, R. Cognitive behavioural processes across psychological disorders: a transdiagnostic approach to research and treatment. Oxford University Press; 2004.

Hautzinger, M. Kognitive Verhaltenstherapie bei Depressionen: Behandlungsanleitungen und Materialien (Vol. 6. überar. Aufl.). Weinheim: Beltz PVU; 2003.

Hayes AM, Beevers CG, Feldman GC, Laurenceau J, Perlman C. Avoidance and processing as predictors of symptom change and positive growth in an integrative therapy for depression. International Journal of Behavioral Medicine. 2005; 12(2):111-122. [PubMed: 15901220]

Hayes AM, Feldman GC, Beevers CG, Laurenceau JP, Cardaciotto LA, Lewis-Smith J. Discontinuities and cognitive changes in an exposure-based cognitive therapy for depression. Journal of Consulting and Clinical Psychology. 2007c; 75(3):409-421. [PubMed: 17563158]

Hayes, AM.; Feldman, GC.; Goldfried, MR. The Change and Growth Experiences Scale (CHANGE): A measure of insight and emotional processing. In: Castonguay, LG.; Hill, C., editors. Insight in psychotherapy. Washington, DC: American Psychological Association; 2006. p. 231-253.

Hayes, AM.; Laurenceau, JP.; Cardaciotto, L. Methods for capturing the process of change. In: Nezu, AM.; Nezu, CM., editors. Evidence-based outcome research: A practical guide to conducting randomized clinical trials for psychosocial interventions. Oxford University Press; 2007a. p. 335-358. 
Hayes AM, Laurenceau J, Feldman G, Strauss JL, Cardaciotto L. Change is not always linear: The study of nonlinear and discontinuous patterns of change in psychotherapy. Clinical Psychology Review. 2007b; 27(6):715-723. [PubMed: 17316941]

Hayes, AM.; Ready, CB.; Yasinski, C. Exposure to emotion in depression: Exposure-Based Cognitive Therapy. In: Thoma, Nathan; McKay, Dean, editors. Engaging emotion in cognitive behavioral therapy: Experiential techniques for promoting lasting change. Guildford Press; 2014. p. 121-145.

Hayes AM, Strauss JL. Dynamic systems theory as a paradigm for the study of change in psychotherapy: An application to cognitive therapy for depression. Journal of Consulting and Clinical Psychology. 1998; 66(6):939-947. [PubMed: 9874907]

Hayes, AM.; Yasinski, C. Pattern destabilization and emotional processing in the context of cognitive therapy for personality disorders. In: Salvatore, S.; Tschacher, W.; Gelo, OC.; Koch, S., editors. Dynamical systems theory in psychotherapy research: A new look at process and outcome, special issue of Frontiers in Psychology in Clinical Settings. 2015.

Hayes AM, Yasinski CW, Ready CB, Laurenceau JP. A method for studying change in psychotherapy from a dynamical systems perspective: Emotional processing, associative networks, and state space grids. Manuscript submitted. 2015

Higginson S, Mansell W, Wood AM. An integrative mechanistic account of psychological distress, therapeutic change and recovery: The Perceptual Control Theory approach. Clinical Psychology Review. 2011; 31:249-259. [PubMed: 20171771]

Howerter A, Hollenstein T, Boon H, Neimeyer K, Brule D. State-space grid analysis: Applications for critical whole systems complementary and alternative medicine research. Forsch Komplementärmedzin. 2012; 19(suppl 1):30-35.

Heron KE, Smyth JM. Ecological momentary interventions: incorporating mobile technology into psychosocial and health behaviour treatments. British Journal of Health Psychology. 2010; 15:139. [PubMed: 19646331]

Hershenberg R, Goldfried MR. Implications of RDoC for the Research and Practice of Psychotherapy. Behavior Therapy. 2015; 46:156-165. [PubMed: 25645165]

Höhn P, Menne-Lothmann C, Peeters F, Nicolson NA, Jacobs N, Derom C, Wichers M. Moment-tomoment transfer or positive emotions in daily life predicts future course of depression in both general population and patient samples. PLoS ONE. 2013; 8(9)

Hollenstein T. State space grids: Analyzing dynamics across development. International Journal of Behavioral Development. 2007; 31:384-396.

Hollenstein T, Lichtwarck-Aschoff A, Potworowski G. A model of socioemotional flexibility at three time scales. Emotion Review. 2013; 5(4):397-405.

Hollon SD, Ponniah K. A review of empirically supported psychological therapies for mood disorders in adults. Depression and Anxiety. 2010; 27(10):891-932. [PubMed: 20830696]

Holmes EA, Craske MG, Graybiel AM. Psychological treatments: A call for mental-health science. Nature. 2014; 511(7509):287-289. [PubMed: 25030152]

Holtzheimer PE, Mayberg HS. Stuck in a rut: rethinking depression and its treatment. Trends in Neuroscience. 2011; 34(1):1-9.

Hölzel L, Härter M, Reese C, Kriston L. Risk factors for chronic depression-A systematic review. Journal of Affective Disorders. 2011; 129(1-3):1-13. [PubMed: 20488546]

Houben M, Van den Noortgate W, Kuppens P. The relation between short term emotion dynamics and psychological well-being: A meta-analysis. Psychological Bulletin. (in press).

Insel TR, Gogtay N. National Institute of Mental Health clinical trials: new opportunities, new expectations. Journal of the American Medical Association, Psychiatry. 2014; 71(7):745-746. [PubMed: 24806613]

Joormann J, Gotlib IH. Emotion regulation in depression: Relation to cognitive inhibition. Cognition and Emotion. 2010; 24:281-298. [PubMed: 20300538]

Joormann J, Tanovic T. Cognitive vulnerability to depression: examining cognitive control and emotion regulation. Current Opinion in Psychology. (in press).

Kashdan TB, Rottenberg J. Psychological flexibility as a fundamental aspect of health. Clinical Psychology Review. 2010; 30(4):467-480. [PubMed: 20381224] 
Kazdin AE. Evidence-based treatments research: advances, limitations, and next steps. American Psychologist. 2011; 66:685-698. [PubMed: 22082384]

Kelso, JAS.; Ding, M.; Schöner, G. Dynamic pattern formation: A primer. Cambridge, MA, US: The MIT Press, Cambridge, MA; 1993.

Koster EHW, De Lissnyder E, Derakshan N, De Raedt R. Understanding depressive rumination from a cognitive science perspective: The impaired disengagement hypothesis. Clinical Psychology Review. 2011; 31:138-145. [PubMed: 20817334]

Koval P, Brose A, Pe ML, Houben M, Erbaş YI, Champagne D, Kuppens P. Emotional inertia and external events: The roles of exposure, reactivity, and recovery. Emotion. (in press).

Koval P, Kuppens P, Allen NB, Sheeber L. Getting stuck in depression: The roles of rumination and emotional inertia. Cognition and Emotion. 2012; 26(8):1412-1427. [PubMed: 22671768]

Koval P, Pe ML, Meers K, Kuppens P. Affect dynamics in relation to depressive symptoms: Variable, unstable or inert? Emotion. 2013; 13(6):1132-1141. [PubMed: 23914765]

Kumar S, Feldman G, Hayes AM. Change in mindfulness and emotion regulation in an integrative therapy for depression. Cognitive Therapy and Research. 2008; 32:734-744.

Kuppens P, Allen NB, Sheeber LB. Emotional inertia and psychological maladjustment. Psychological Science. 2010; 21(7):984-991. [PubMed: 20501521]

Kuyken W, Watkins E, Holden E, White K, Taylor RS, Byford S, Dalgleish T. How does mindfulnessbased cognitive therapy work? Behavioural Research and Therapy. 2010; 48:1105-1112. http:// dx.doi.org/10.1016/j.brat.2010.08.003.

Lamey A, Hollenstein T, Lewis MD, Granic I. GridWare (Version 1.1). [Computer software]. 2004 http://statespacegrids.org.

Lang PJ. Imagery in therapy: An information processing analysis of fear. Behavior Therapy. 1977; 8(5):862-886.

Laurenceau J, Hayes AM, Feldman GC. Some methodological and statistical issues in the study of change processes in psychotherapy. Clinical Psychology Review. 2007; 27(6):682-695. [PubMed: 17328996]

Lieberman MD, Eisenberger NI, Crockett MJ, Tom SM, Pfeifer JH, Way BM. Putting feelings into words: Affect labeling disrupts amygdala activity in response to affective stimuli. Psychological Science. 2007; 18(5):421-428. [PubMed: 17576282]

Lewis MD. Bridging emotion theory and neurobiology through dynamic systems modeling. Behavioral and Brain Sciences. 2005; 28(2):169-245. [PubMed: 16201458]

Lorenzo-Luaces L, German RE, DeRubeis RJ. It's complicated: The relation between cognitive change procedures, cognitive change, and symptom change in cognitive therapy for depression. Clinical Psychology Review. (this issue).

Malogiannis JA, Arntz A, Spyropoulou A, Tsartsara E, Aggeli A, Karveli S, Zervis I. Schema therapy for patients with chronic depression: A single case series study. Journal of Behavior Therapy and Experimental Psychiatry. 2014; 45(3):319-329. [PubMed: 24650608]

Nadel L, Hupbach A, Gomez R, Newman-Smith K. Memory formation, consolidation and transformation. Neuroscience and Biobehavioral Reviews. 2012; 36(7):1640-1645. [PubMed: 22465050]

Pascual-Leone A, Greenberg LS. Emotional processing in experiential therapy: Why "the only way out is through.”. Journal of Consulting and Clinical Psychology. 2007; 75(6):875-887. [PubMed: 18085905]

Pe ML, Kircanski K, Thompson RJ, Bringmann LF, Tuerlinckx F, Mestdagh M, Gotlib IH. Emotionnetwork density in major depressive disorder. Clinical Psychological Science. 2015; 3:292-300.

Pe ML, Raes F, Kuppens P. The cognitive building blocks of emotion regulation: Ability to update working memory moderates the efficacy of rumination and reappraisal on emotion. Plos One. $2013 ; 8(7)$

Pizzagalli DA, Pizzagalli DA. Depression, stress, and anhedonia: toward a synthesis and integrated model. Annual Review of Clinical Psychology. 2014; 10:393-423.

Pos AE, Greenberg LS, Goldman RN, Korman LM. Emotional processing during experiential treatment of depression. Journal of Consulting and Clinical Psychology. 2003; 71(6):1007-1016. [PubMed: 14622076] 
Powers MB, Halpern JM, Ferenschak MP, Gillihan SJ, Foa EB. A meta-analytic review of prolonged exposure for posttraumatic stress disorder. Clinical Psychology Review. 2010; 30(6):635-641. [PubMed: 20546985]

Ramseyer F, Kupper Z, Caspar F, Znoj H, Tschacher W. Time-series panel analysis (TSPA): multivariate modeling of temporal associations in psychotherapy process. Journal of Consulting and Clinical Psychology. 2014; 82(5):828-838. [PubMed: 24932566]

Ready CB, Hayes AM, Yasinski CW, Webb CM, Gallop R, Deblinger E. Overgeneralized beliefs, new learning, and symptom outcome in Trauma-Focused Cognitive Behavioral Therapy for childhood trauma. Behavior Therapy. (in press).

Resick, PA.; Monson, CM.; Chard, KM. Cognitive processing therapy: Veteran/military version. Washington, DC: Department of Veterans Affairs; 2014.

Salvatore S, Tschacher W. Time dependency of psychotherapeutic exchanges: The contribution of the theory of dynamic systems in analyzing process. Frontiers in Psychology. 2012; 3

Scheffer M, Carpenter SR, Lenton TM, Bascompte J, Brock W, Dakos V, et al. Anticipating critical transitions. Science. 2012; 338:344-348. [PubMed: 23087241]

Schiepek, G.; Eckert, H.; Aas, B.; Wallot, S.; Wallot, A. Integrative psychotherapy: A feedback-driven dynamic systems approach. Göttingen, Germany: Hogrefe Publishing; 2015.

Schiepek G, Fartacek C, Sturm J, Kralovec K, Fartacek R, Plöderl M. Nonlinear dynamics:Theoretical perspectives and application to suicidology. Suicide and Life-Threatening Behavior. 2011; 41:661-675. [PubMed: 22145825]

Schiepek G, Strunk G. The identification of critical fluctuations and phase transitions in short term and coarse-grained time series-a method for the real-time monitoring of human change processes. Biological Cybernetics. 2010; 102:197-207. [PubMed: 20084517]

Schiepek G, Tominschek I, Heinzel S, Aigner M, Dold M, Unger A, Karch S. Discontinuous patterns of brain activation in the psychotherapy process of obsessive-compulsive disorder: Converging results from repeated fMRI and daily self-reports. PloS ONE. 2013; 8(8)

Solomon DA, Keller MB, Leon AC, Mueller TI, Lavori PW, Shea MT, Endicott J. Multiple recurrences of major depressive disorder. The American Journal of Psychiatry. 2000; 157(2): 229-233. [PubMed: 10671391]

Spijker J, van Straten A, Bockting CLH, Meeuwissen JAC, van Balkom AJLM. Psychotherapy, antidepressants, and their combination for chronic major depressive disorder: A systematic review. The Canadian Journal of Psychiatry / La Revue Canadienne De Psychiatrie. 2013; 58(7): 386-392.

Steinacher A, Wright KA. Relating the bipolar spectrum to dysregulation of behavioral activation: a perspective from dynamical modelling. PLoS ONE. 2013; 8(5):e63345. [PubMed: 23691030]

Tabibnia G, Lieberman MD, Craske MG. The lasting effect of words on feelings: Words may facilitate exposure effects to threatening images. Emotion. 2008; 8(3):307-317. [PubMed: 18540747]

Teasdale JD. Emotional processing, three modes of mind and the prevention of relapse in depression. Behaviour Research and Therapy. 1999; 37(Suppl 1):S53-S77. [PubMed: 10402696]

Teasdale JD, Segal ZV, Williams JMG, Ridgeway VA, Soulsby JM, Lau MA. Prevention of relapse/ recurrence in major depression by mindfulness-based cognitive therapy. Journal of Consulting and Clinical Psychology. 2000; 68:615-623. [PubMed: 10965637]

Thelen, E.; Smith, LB. A dynamic systems approach to the development of cognition and action. Cambridge, MA, US: The MIT Press, Cambridge, MA; 1994.

Thompson RJ, Mata J, Jaeggi SM, Buschkuehl M, Jonides J, Gotlib IH. The everyday emotional experience of adults with major depressive disorder: Examining emotional instability, inertia, and reactivity. Journal of Abnormal Psychology. 2012; 121(4):819-829. [PubMed: 22708886]

Trew JL. Exploring the roles of approach and avoidance in depression: An integrative model. Clinical Psychology Review. 2011; 31(7):1156-1168. [PubMed: 21855826]

Vallacher RR, Read SJ, Nowak A. The dynamical perspective in personality and social psychology. Personality and Social Psychology Review. 2002; 6(4):264-273. doi:http://dx.doi.org/10.1207/ S15327957PSPR0604_01.

van Geert P, van Dijk M. Focus on variability: New tools to study intra-individual variability in developmental data. Infant Behavior \& Development. 2002; 25(4):340-374. 
van de Leemput IA, Wichers MA, Carmer AOJ, Borsboom D, Tuerlinckx F, Kuppens P, Scheffer M. Critical slowing down as early warning for the onset and termination of depression. Proceedings of the National Academy of Sciences. 2014; 111(1):87-92.

Watkins ER. Constructive and unconstructive repetitive thought. Psychological Bulletin. 2008; 134(2): 163-206. [PubMed: 18298268]

Watkins ER, Nolen-Hoeksema S. A habit-goal framework of depressive rumination. Journal of Abnormal Psychology. 2014; 123(1):24-34. [PubMed: 24661156]

Waugh CE, Koster EHW. A resilience framework for promoting stable remission from depression. Clinical Psychology Review. (this issue).

Weingarten CP, Strauman TJ. Neuroimaging for psychotherapy research: Current trends. Psychotherapy Research. 2015; 2(2):185-213. [PubMed: 24527694]

Wheatley J, Brewin CR, Patel T, Hackmann A, Wells A, Fisher P, Myers S. "I'll believe it when I can see it": Imagery rescripting of intrusive sensory memories in depression. Journal of Behavior Therapy and Experimental Psychiatry. 2007; 38(4):371-385. [PubMed: 17915192]

Wichers M. The dynamic nature of depression: A new micro-level perspective of mental disorder that meets current challenges. Psychological Medicine. 2014; 44(7):1349-1360. [PubMed: 23942140]

Wichers M, Simons CJP, Kramer IMA, Hartmann JA, Lothmann C, Myin-Germeys I, van Bemmel AL, Peeters F, Delespaul P, van Os J. Momentary assessment technology as a tool to help patients with depression help themselves. Acta Psychiatrica Scandinavica. 124:262-272. [PubMed: 21838742]

Whitmer AJ, Gotlib IH. An attentional scope model of rumination. Psychological Bulletin. 2013; 139:1036-1061. [PubMed: 23244316]

Young, JE.; Klosko, JS.; Weishaar, ME. Schema therapy: A practitioner's guide. New York, NY, US: Guilford Press; 2003. 


\section{Highlights}

- Dynamic systems theory is proposed as a framework for understanding the

- chronicity of depression.

- Principles of dynamic systems and modern learning theory are applied to the

- treatment of depression.

- A dynamic systems model of change is investigated.

- Avenues for future treatment innovation are discussed. 
Panel A: The maladaptive (depressive) network is densely interconnected and elaborated with perpetuating processes that inhibit change. The positive network is less developed.

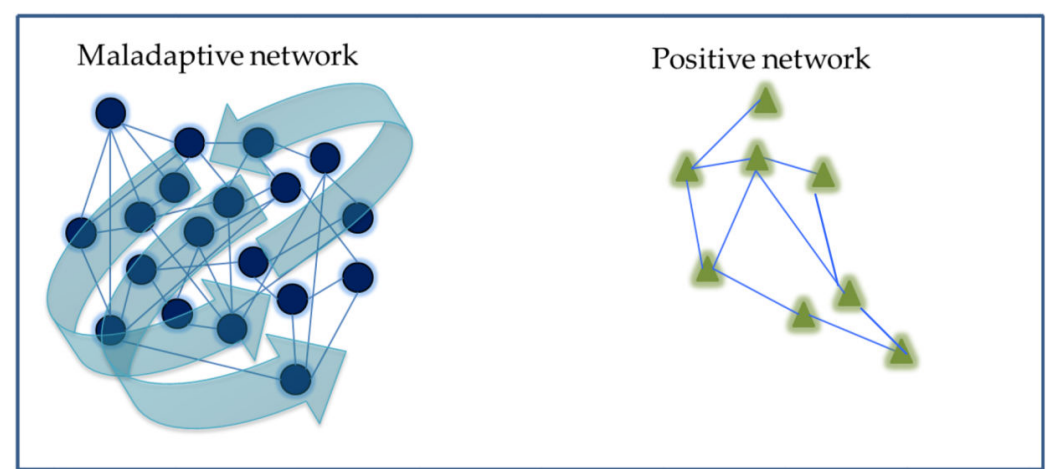

Panel B: Therapy can activate (red lines) and destabilize the maladaptive network and facilitate constructive emotional processing.

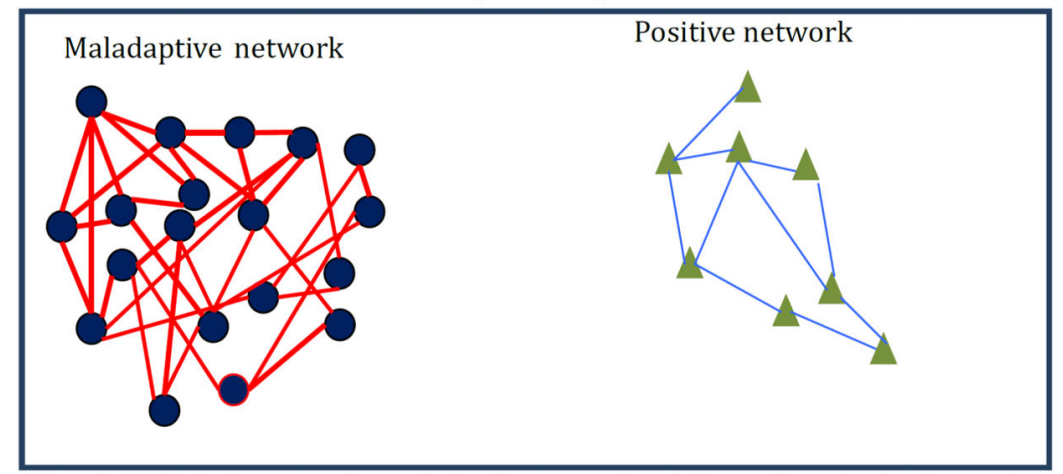

Panel C: With therapy, the maladaptive network might weaken. Activating and exercising the positive network can create upward spirals of positive functioning.

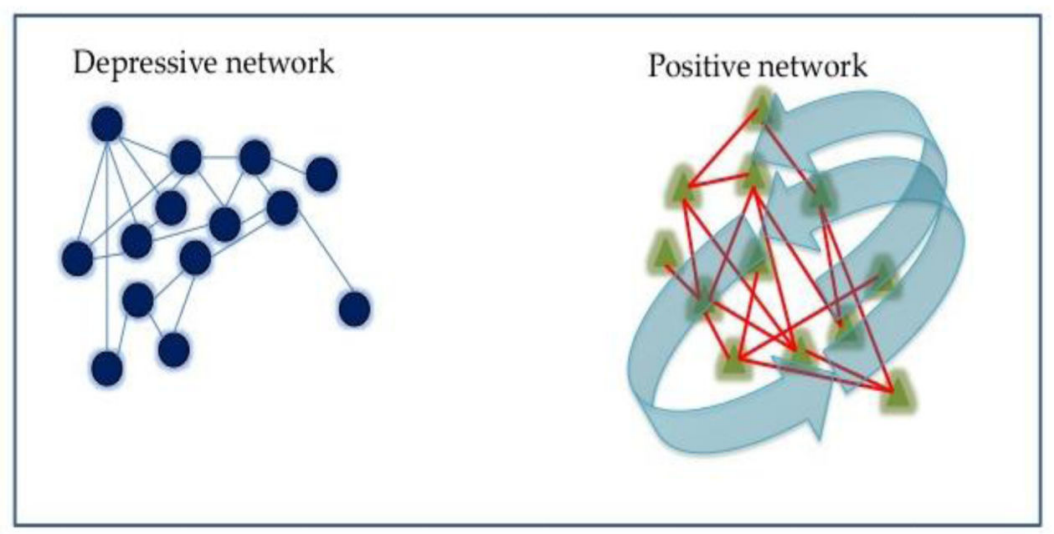

Figure 1. Network Destabilization and Transition (NDT) Model 


\section{Examples of network behavior in state-space grids showing low dispersion $(A)$ and high dispersion (B).}

\section{Panel A}

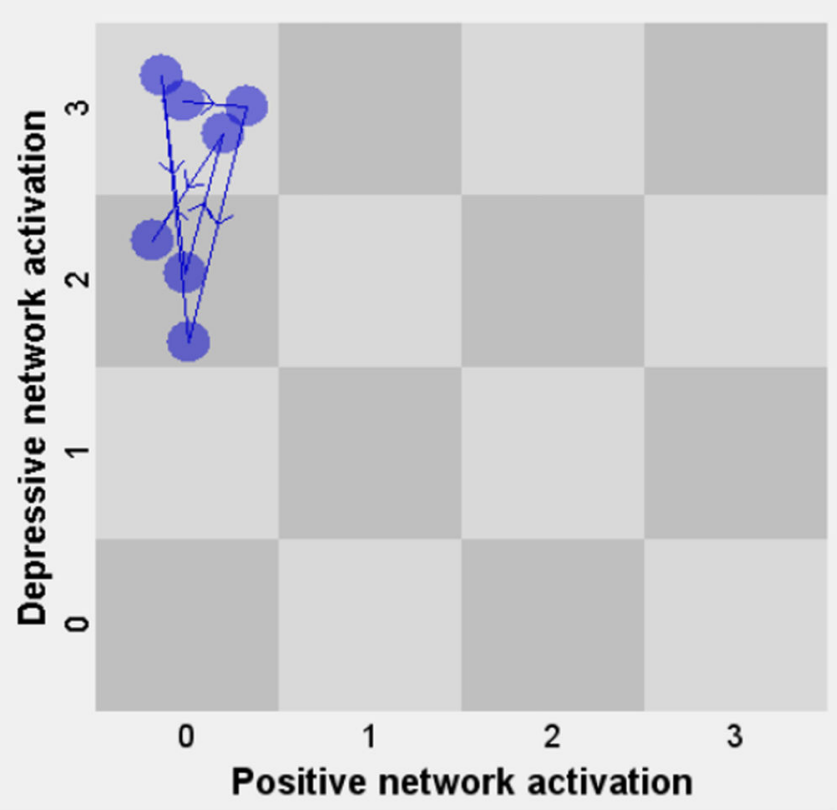

Panel B

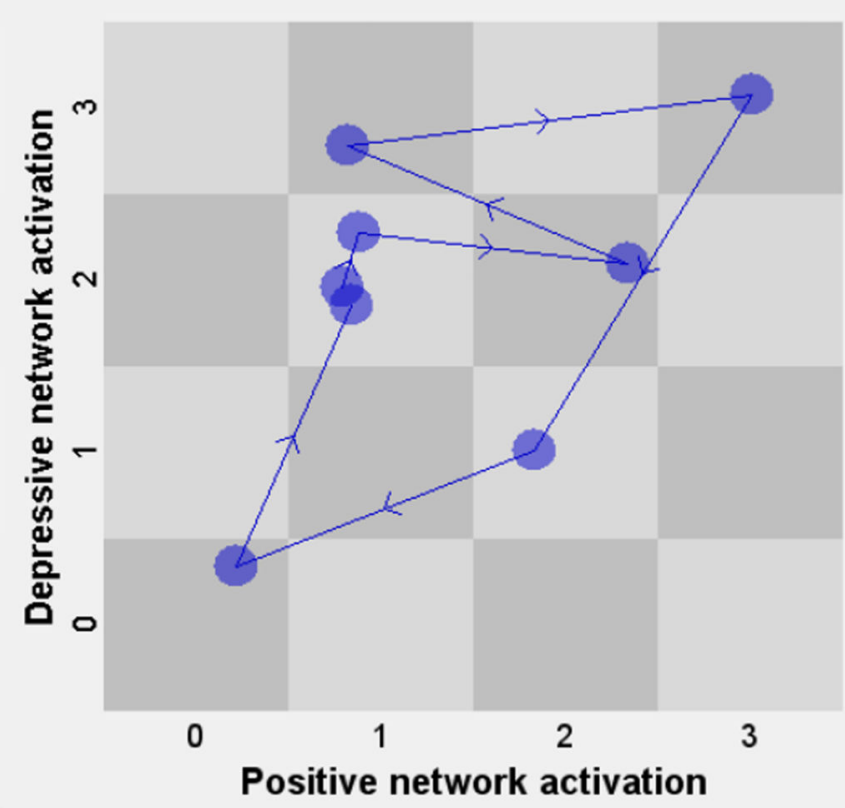

Figure 2. Positive and depressive network activation in a Gridware state space grid This example depicts network activation scores for a participant during one of three phases of therapy. Depressive and positive network activation scores are plotted for each of eight sessions in a phase of treatment. A node (cognitive, emotional, behavioral functioning coded using the CHANGE rating system) of the depressive or positive network is considered "activated" if it is coded as occurring at a moderate (rating of 2) to high (3) level. For example, the first circle on the far left of Panel A depicts a session narrative with a score of 2 nodes activated in the depressive network and 0 in the positive network (2,0 is plotted). Behavior follows the direction of the arrows across the sessions in that treatment phase. The behavior of networks can be mapped and quantified across the course of treatment. From these data, network dispersion (above) and extent of negative and positive network region activation (Figure 3) can be calculated. Panel A depicts low dispersion across the grid, whereas Panel B depicts higher dispersion. Dispersion scores can be used to approximate network stability or destabilization. 


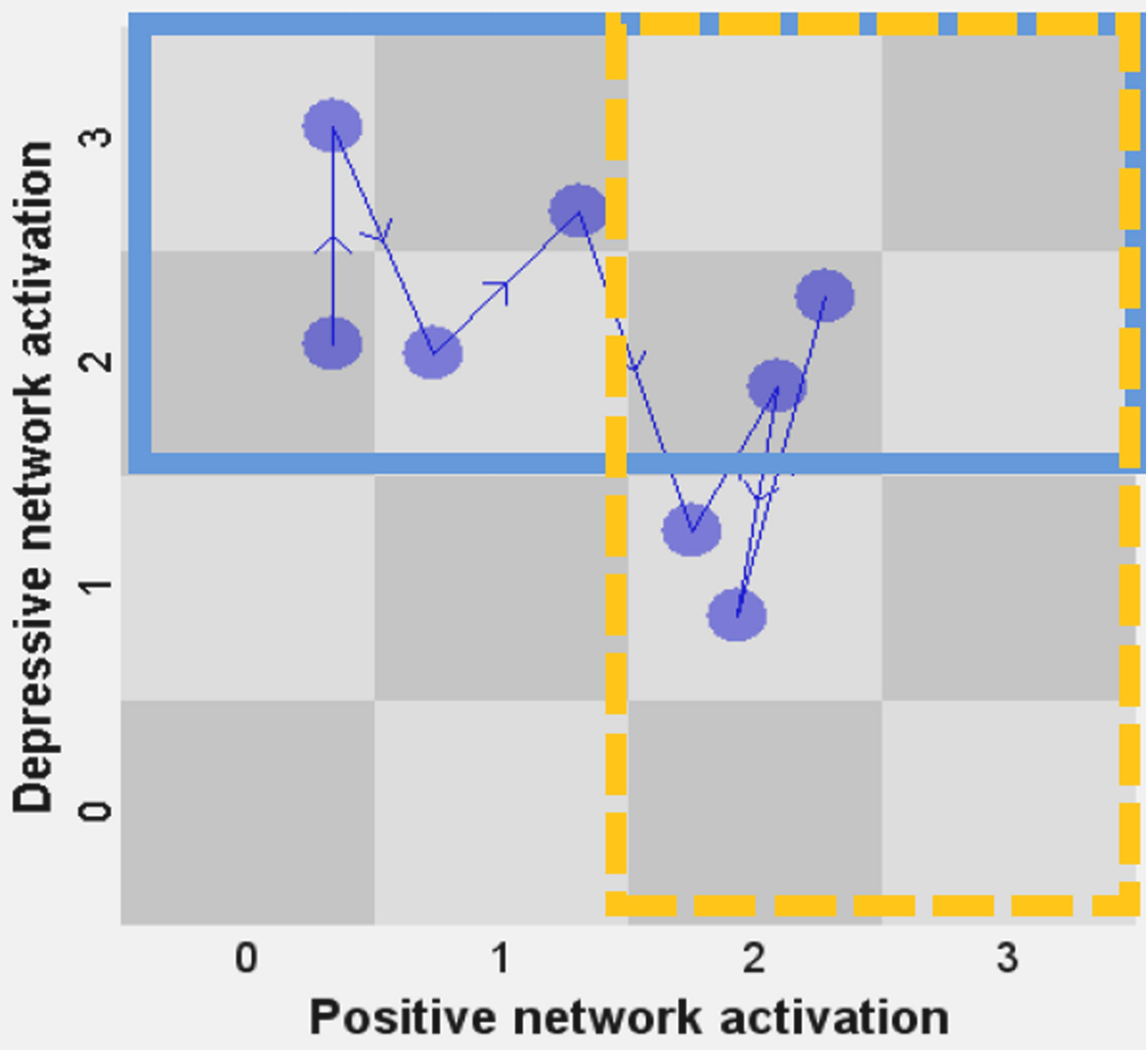

Figure 3. Depressive and positive regions of activation

Areas of state-space grids were used to determine depressive and positive network activation for participants within each treatment phase. Behavior in the depressive region (solid line) was defined as any session in which the total depressive network activation score was moderate to high (two or more nodes were activated in the narrative from that session). Behavior in the positive region (dashed line) was calculated in the same way, using the positive network activation scores. Extent of network activation in the depressive and positive regions was calculated by dividing the number of sessions a participant spent in the depressive or positive regions of the state-space grid by the total number of sessions during that phase. In this example, $75 \%$ of the scores in that treatment phase fell in the depressive region and $50 \%$ in the positive region. Such a pattern can characterize a system in transition, 
as depressive and positive network activation are co-occurring. It is also possible to define nonoverlapping regions, but this co-occurence is of interest in our research. 